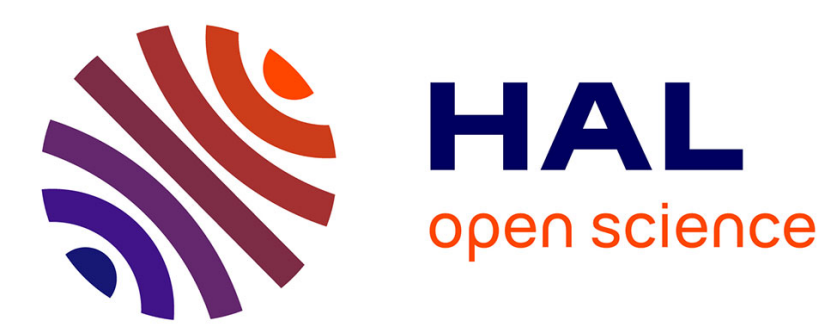

\title{
Polycyclic Aromatic Hydrocarbon Growth by Diradical Cycloaddition/Fragmentation
}

\author{
A. Comandini, S. Abid, N. Chaumeix
}

\section{To cite this version:}

A. Comandini, S. Abid, N. Chaumeix. Polycyclic Aromatic Hydrocarbon Growth by Diradical Cycloaddition/Fragmentation. Journal of Physical Chemistry A, 2017, 121 (31), pp.5921-5931. 10.1021/acs.jpca.7b05562 . hal-02417176

\section{HAL Id: hal-02417176 https://hal.science/hal-02417176}

Submitted on 8 Feb 2022

HAL is a multi-disciplinary open access archive for the deposit and dissemination of scientific research documents, whether they are published or not. The documents may come from teaching and research institutions in France or abroad, or from public or private research centers.
L'archive ouverte pluridisciplinaire HAL, est destinée au dépôt et à la diffusion de documents scientifiques de niveau recherche, publiés ou non, émanant des établissements d'enseignement et de recherche français ou étrangers, des laboratoires publics ou privés. 


\title{
Polycyclic Aromatic Hydrocarbon Growth by Diradical Cycloaddition/Fragmentation
}

\author{
A. Comandini*, S. Abid, N. Chaumeix \\ Institut de Combustion Aérothermique Réactivité et Environnement \\ INSIS-CNRS \\ 1C Avenue de la Recherche Scientifique, 45071 Orléans cedex 2, France \\ * Corresponding author: andrea.comandini@cnrs-orleans.fr
}

Published on Journal of Physical Chemistry A (J Phys Chem A, 121, 5921-5931, 2017) 
Abstract: The recent theoretical and experimental investigations on the growth of polycyclic aromatic hydrocarbons in pyrolytic environments highlight the possible role of the 1,4-cycloaddition/fragmentation (1,4-CAF) steps in the formation of PAH intermediates and consequently soot. The present theoretical study explores the possibility to generalize such mechanism to reactions involving various diradical compounds and stable multi-ring structures. The calculations were performed using the uB3LYP/6$311 \mathrm{G}(\mathrm{d}, \mathrm{p})$ method and different composite methods, when possible, for more accurate energy estimates. First the complex potential energy surface for the reactions between o-benzyne and naphthalene was investigated, including the 1,4-CAF mechanism to form anthracene and acetylene through the dibenzobicyclo[2.2.2] octatriene intermediate. Moreover, the products of the addition reactions to the $\alpha$ and $\beta$-carbons and to the ring-junction atoms were determined. The energies for the optimized CAF structures, which constitute the most-favorable pathway from an energetic point of view, were calculated using CBS-QB3, G3(MP2)B3, and G3B3 methods and compared to the corresponding values for the obenzyne + benzene reactions. Additional calculations were focused on the possible CAF reactions between o-benzyne and larger multi-ring structures, such as anthracene, phenanthrene, pyrene, and the four-ring PAHs. The results indicate how the energetics of such reactions is influenced by both the size of the PAH compound and the position of the carbon atoms involved. In the second part of the study, the energy barriers necessary to form multi-ring diradicals from the corresponding radical molecules were analyzed at a G3(MP2)B3 level of theory. Such calculations are preliminary for the subsequent study on the CAF reactions between the different diradical intermediates and benzene. While the size of the diradical does not affect significantly the energy barriers, the position of the diradical site is critical. The concerted Diels-Alder reactions between the naphthynes and naphthalene were also studied in order to further clarify the analogies between the reactions involving different diradicals. Based on these results, kinetic considerations were provided based on the comparison with the simpler o-benzyne + benzene system, although further higher-level calculations and master equation kinetic analyses will be required to derive the general kinetic rules. 


\section{Introduction}

The reduction of soot emissions from modern, high-pressure combustion devices represents one of the principal milestones towards next-generation, clean technologies. Nevertheless, current knowledge on soot chemical kinetics is still rather incomplete. In particular, the growth of polycyclic aromatic hydrocarbons (PAHs) constitutes one of the most influential but uncertain processes involved in soot formation. The uncertainties derive from two main aspects, the difficulties encountered in performing experimental and theoretical studies on high molecular-weight compounds and the large number of reaction pathways responsible for the appearance of the multi-ring intermediates from real fuels. Doubts were also raised on the possibility to arrive at a solution of such a complex problem ${ }^{1}$. Yet new advances in computational capabilities represent a valuable resource for the implementation of investigations on novel potential energy surfaces for reactions between larger and larger compounds. In particular, recent theoretical studies highlight the presence of a relatively low pathway involving 1,4-cycloaddition of singlet o-benzyne to benzene and subsequent fragmentation to form naphthalene and acetylene $e^{2,3}$. This pathway seems to be energetically favorable compared to the addition step which proceeds through formation of a C-C bond followed by subsequent isomerization reactions. Based on the CBS-QB3 single-point energy calculations by Shukla et al. ${ }^{3}$, the cycloaddition entrance barrier is around $10 \mathrm{kcal} / \mathrm{mol}$ lower than the addition barrier, although the latter may be affected by large uncertainties due to spin contamination. The pioneering experimental works on aryne compounds also indicate the reaction of o-benzyne and benzene (deuterated and not) as responsible for the formation of different PAH intermediates ${ }^{4-6}$. In particular, Friedman and Lindow $^{6}$ performed experiments on the pyrolysis of phthalic anhydride in benzene and benzene-d6 at $690^{\circ} \mathrm{C}$ and measured the $\mathrm{PAH}$ products which consisted mainly of naphthalene $(80 \%)$ from the cycloaddition/fragmentation (CAF) steps (as hypothesized by the authors). Other detected products included biphenyl (9\%), acenaphthylene (6\%), and acenaphthene (5\%) from other pathways. Experimental evidences for the formation of the second-ring structure from the benzene + o-benzyne reaction were also obtained by Comandini et al. ${ }^{7}$ at conditions relevant to modern engines and turbines (high-pressure, high- 
temperature). In this case, o-benzyne is produced from both the thermal decomposition of the phenyliodide fuel and by the self-reaction between phenyl radicals (as suggested by Tranter et al. ${ }^{8}$ ). The modeling results presented in Ref. 7 highlight the central role of o-benzyne in the growth to larger ring structures (up to four-rings) including naphthalene from the above-mentioned CAF mechanism. Even when large amounts of acetylene were added to the initial fuel mixture, the o-benzyne + benzene reaction was responsible for the formation of naphthalene at high temperatures $(\sim 1450 \mathrm{~K})$ compared to the lower temperature experiments (below $1250 \mathrm{~K}$ ) where the hydrogen migration from the ring to the vinyl moiety of the $\mathrm{C}_{6} \mathrm{H}_{5} \mathrm{C}_{2} \mathrm{H}_{2}$ radical (produced by the addition of $\mathrm{C}_{2} \mathrm{H}_{2}$ to the phenyl radical) followed by $\mathrm{C}_{2} \mathrm{H}_{2}$ addition and cyclization ${ }^{9,10}$ play a dominant role. In a different shock tube study, Colket and Seery ${ }^{11}$ investigated the pyrolysis of $1 \%$ toluene at $10 \mathrm{~atm}$ and $600 \mu$ s reaction time using gas chromatography as detection technique. The resulting species profiles have been recently used by Yuan et al. ${ }^{12}$ for the validation of a detailed and comprehensive model for toluene pyrolysis and oxidation. The kinetic analyses indicate that the main formation pathway to naphthalene at such high pressure conditions involves the CAF sequence between o-benzyne, formed through thermal decomposition of the benzyl radical $^{13}$, and benzene (mainly from the ipso-addition reaction of toluene with $\mathrm{H}$ ).

The experimental, modeling, and theoretical investigations presented in the previous paragraph indicate that at the high-pressure pyrolytic conditions encountered in shock tube experiments the o-benzyne + benzene cycloaddition reactions may play a key role for the growth to the second-ring. Motivated by such results, Comandini and Brezinsky ${ }^{14}$ extended their theoretical study on the radical $/ \pi$-bond addition between single-ring aromatic hydrocarbons ${ }^{2}$ to investigate the reactions between o-benzyne and cyclic $\mathrm{C} 5$ hydrocarbons, including cyclopentadiene. Also in this case, an energetically favored CAF pathway leading to indene + acetylene through the formation of a bicyclo intermediate (benzonorbornadiene) is identified. The present theoretical work will explore the possibility to further extend the diradical cycloaddition/fragmentation mechanism to larger multi-ring structures. First, the potential energy surface for the reactions between o-benzyne and naphthalene will be investigated in detail as a relatively simple 
example of reaction system involving a diradical compound and a polycyclic aromatic hydrocarbon. In addition, the CAF steps between o-benzyne and the typical three- and four-ring aromatics will be analyzed in order to determine the influence of the molecular size of the reactants on the energetics of the single kinetic reactions. Finally, the formation of diradical species other than o-benzyne from the thermal decomposition of PAH radicals and their cycloaddition/fragmentation reactions with other aromatic intermediates will be evaluated as possible pathways for the rapid growth of multi-ring structures.

\section{Computational Methods}

All geometry optimizations were performed using the Becke three parameter hybrid method ${ }^{15}$ with the Lee-Yang-Parr correlation functional approximation ${ }^{16}$ with spin-unrestricted, symmetry-broken wave functions (uB3LYP) and Pople's valence triple- $\zeta$ basis set including polarization functions ${ }^{17}$ (6$311 G(d, p))$. All the structure optimizations of the local minima and saddle points were performed using the Gaussian G09 program package ${ }^{18}$. The saddle points, characterized by exactly one vibrational mode with an imaginary frequency, were identified by similarity with other well-known reaction systems and with the help of potential energy surface scans. Visualization of the movement of atoms in the imaginary frequency mode was used to test if the atoms move toward the reactants and the products. In addition, when necessary, intrinsic reaction coordinate (IRC) calculations ${ }^{19}$ were carried out on the optimized transition state structures to confirm that the specific transition state is appropriate for the reaction path under consideration. The estimated values of the energies and zero-point vibrational energy (ZPVE) corrections from the $\mathrm{uB} 3 \mathrm{LYP} / 6-311+\mathrm{G}(\mathrm{d}, \mathrm{p})$ calculations were used to derive the potential energy surfaces presented in the manuscript, unless otherwise mentioned. Multireference methods with appropriate active spaces would definitely provide more accurate results especially in the case of spin contamination, but this kind of calculation would require computational resources which are beyond the capabilities available to the authors. However, the relative energies obtained with the present method are sufficiently accurate to draw conclusions on the accessibility of the various reaction pathways as well as to provide indications of the relative importance of the different channels. Additional single-point calculations based on the 
B3LYP/6-311G(d,p) optimized structures were performed using different composite methods, such as $\mathrm{CBS} \mathrm{QB} 3^{20,21}$, and G3(MP2)B3/G3B3 ${ }^{22}$, as specified in the text. These calculations, which are not affected by spin contamination, are expected to be more accurate than the corresponding B3LYP hybrid density functional calculations.

\section{Results and Discussion}

\section{1. o-Benzyne + naphthalene}

The potential energy surface (PES) for the reactions between o-benzyne and naphthalene represents the simplest case of reaction systems which involve a cyclic C6 diradical and a multi-ring compound. The results of the calculations performed at the B3LYP/6-311G(d,p) level of theory are presented in Figure 1. For clarity, the PES has been divided into three parts and all the energies are relative to the energy of the reactants. The panel (a) of the figure contains the two energetically most favorable entrance channels, the Diels-Alder concerted step to form the bicyclo intermediate $\mathbf{S 1}$ (dibenzobicyclo[2.2.2]octatriene) and the addition to the $\alpha$-carbon to the $\mathbf{S 3}$ diradical. Based on the B3LYP/6-311G(d,p) energies, the entrance barriers differ by around $4 \mathrm{kcal} / \mathrm{mol}$ in favor of the cycloaddition. It is important to underline how this value may be affected by large errors due to the spin contamination in the calculation of the optimized TS3 structure. As for o-benzyne + benzene, the bicyclo stable intermediate can undergo fragmentation, in this case forming anthracene (S2) and acetylene, with an energy barrier which is relatively low compared to the energy necessary to re-dissociate the compound into o-benzyne and naphthalene. A more detailed analysis of the energies for the CAF steps will be performed later in the manuscript using different composite methods. On the other hand, the adduct $\mathbf{S 3}$ may easily undergo rotation around the C-C bond between the rings forming $\mathbf{S} 4$ (barrier of $\sim 3 \mathrm{kcal} / \mathrm{mol}$ ). At this point, the radical site of the aromatic $\mathrm{C6}$ ring can quickly form a bond with the carbon in position 4 to form dibenzobicyclo[2.2.2]octatriene or in position 2 leading to $\mathbf{S 6}$, one of the isomers of benzodihydro-biphenylene. There exists a third possibility, the formation of a bond between the above mentioned radical and the ring-junction carbon atom to form 
S5 but such reaction is characterized by a relatively large barrier compared to the previous two cases (the difference is around $10 \mathrm{kcal} / \mathrm{mol}$ based on the present level of theory). If enough energy is provided to the system, both dibenzobicyclo[2.2.2]octatriene and $\mathbf{S 6}$ benzodihydro-biphenylene may convert into anthracene and acetylene, but while in the former case this process includes a single-step reaction as described above, the $\mathbf{S 6}$ intermediate undergoes numerous isomerization steps. S6 is the most stable compound in the pathway towards the formation of three fused-rings. Indeed, both the reverse reaction to S4 and the three subsequent reactions through TS21, TS22, and TS23 are endothermic: the ring expansion to 1,2:4,5-dibenzo-cyclooctatetraene (S16), followed by ring contraction to $\mathbf{S 1 7}$ and the $\beta$-scission to form a $\mathrm{C}_{14} \mathrm{H}_{10} \mathrm{C}_{2} \mathrm{H}_{2}$ diradical intermediate (S18). Once formed, this intermediate may quickly isomerize changing the orientation of the $\mathrm{C}_{2} \mathrm{H}_{2}$ moiety and finally undergo a second $\beta$-scission to anthracene + acetylene. Based on the B3LYP/6-311G(d,p) energies the entire pathway from $\mathbf{S 3}$ to these products lies below the initial TS3 transition state energy. The third, energetically less-favored pathway through S5 proceeds through a relatively small barrier $(\sim 5 \mathrm{kcal} / \mathrm{mol})$ to form the very stable 1,2:3,4dibenzocyclooctatetraene (S7, relative energy of around $-53 \mathrm{kcal} / \mathrm{mol})$. Two isomerization steps are possible, although the corresponding barriers are higher than the reverse barrier to S5. The first, lowerenergy pathway involves an internal bending of the $\mathbf{S 7}$ structure to $\mathbf{S 8}$ followed by ring contraction to $\mathbf{S 9}$. S9 contains three C6 fused-rings. As for the case of $\mathbf{S 1 7}, \beta$-scission may lead to a $\mathrm{C}_{14} \mathrm{H}_{10} \mathrm{C}_{2} \mathrm{H}_{2}$ diradical intermediate (S10) although the corresponding reaction barrier is relatively high $(\sim 50 \mathrm{kcal} / \mathrm{mol})$ even compared to the ring expansion reaction back to $\mathbf{S 8}(\sim 39 \mathrm{kcal} / \mathrm{mol})$. On the other hand, once formed $\mathbf{S 1 0}$ quickly isomerizes to $\mathbf{S 1 1}$ which finally undergoes $\beta$-scission to phenanthrene $(\mathbf{S 1 2})+$ acetylene. The second pathway from the ring expanded $\mathbf{S} 7$ leads to the formation of the same products (phenanthrene + $\mathrm{C}_{2} \mathrm{H}_{2}$ ) but it involves intermediate steps characterized by higher energies. In particular, the reverse of the ring contraction reaction which leads to the formation of $\mathbf{S 1 3}$ is barrierless, thus the flux through such path is expected to be low. The subsequent $\beta$-scission reaction through TS16 is the only step where the energy is higher than the entrance barrier (TS3); the global energy barrier required to overcome such transition 
state from $\mathbf{S} 7$ is very high $(\sim 76 \mathrm{kcal} / \mathrm{mol})$. The diradical formed from the $\beta$-scission reaction through TS16 may undergo several isomerization steps to S10, S11, or S15 and subsequent acetylene loss.

The second portion of the PES for the reactions between o-benzyne and naphthalene, reported on panel (b) of Figure 1, includes the other two possible additions to the $\beta$-carbon and to the ring-junction carbon atom. In the first case, the entrance barrier through TS27 is just few $\mathrm{kcal} / \mathrm{mol}$ higher than the one for the addition to the $\alpha$-carbon. The resulting diradical structure easily rotates around the $\mathrm{C}$-C single bond between the rings forming $\mathbf{S 2 2}$ which may undergo various isomerization steps (similarly to $\mathbf{S 4}$, panel (a)). The formation of a single bond between the radical site of the C6 ring and the other $\beta$-carbon on the naphthalene-like structure leads to the benzodihydro-biphenylene isomer $\mathbf{S 2 3}$ which can undergo ring expansion to the stable S24 intermediate (1,2:5,6-dibenzo-cyclooctatetraene). A second possible pathway involves a similar barrier ( $7 \mathrm{kcal} / \mathrm{mol})$ through $\mathbf{T S 3 2}$ leading to the formation of a bond between the radical site and the opposite ring-junction carbon atom. The resulting bicyclo $\mathbf{S 2 5}$ intermediate is not as stable as $\mathbf{S 1}$, the product of the 1,4-cycloaddition, but it can undergo fragmentation to phenanthrene + acetylene through a barrier of around $31 \mathrm{kcal} / \mathrm{mol}$ (the reverse barrier to the diradical $\mathbf{S 2 2}$ is $\sim 5 \mathrm{kcal} / \mathrm{mol}$ higher, based on the B3LYP/6-311G(d,p) calculations). There exists another possible isomerization of the $\mathbf{S 2 2}$ intermediate to $\mathbf{S 6}$ which is analogous to the $\mathbf{S 4} \rightarrow \mathbf{S 6}$ step. On the other hand, an analogous transition state could not be found. The energy scan obtained varying the C-C distance starting from the optimized S22 structure to S6 indicate that the formation of the bond occurs without any barrier (Figure 2). In this case, a transition state structure could be identified among the optimized scan structures in correspondence with the early rotation around the $\mathrm{C}-\mathrm{C}$ single bond. The corresponding step characterized by negligible energy increment through the transition state is represented by the dash line in Figure 1, panel (b). Further analyses with more accurate level of theories need to be implemented in order to confirm the validity of such path. The subsequent reactions involving $\mathbf{S 6}$ and leading to the formation of anthracene + acetylene have been described in the previous paragraph and reported in panel (a) of Figure 1. While the additions to the $\alpha$ - and $\beta$-carbons require similar energies to overcome the corresponding entrance barriers, the 
addition to the ring-junction carbon atoms leads to the formation of an highly-distorted structure (S26) characterized by a relatively high energy $(\sim 26 \mathrm{kcal} / \mathrm{mol})$. Consequently this should be the least probable reaction pathway. After the rotation around the single C-C bond to form $\mathbf{S 2 7}$, a second bond between the C6 and the C10 structures may be formed through relatively low barriers (few $\mathrm{kcal} / \mathrm{mol}$ ) leading to $\mathbf{S 5}$ (bond with the $\alpha$-carbon) or $\mathbf{S 2 8}$ (bond with the second ring-junction carbon atom). Other reactions of the S5 intermediate have been already discussed in relation to the addition to the $\alpha$-carbon. A third isomerization of the $\mathbf{S 2 7}$ diradical is possible, with the formation of a bond between the radical site of the C6 ring and the opposite $\beta$-carbon forming $\mathbf{S 2 5}$. In this case, no transition state could be found (the scan over the bond distance does not highlight any barrier for the bond closure) and further, more accurate calculations are necessary in order to clarify the presence of such reaction step. Finally, the benzodihydrobiphenylene isomers (S6 and S23) may undergo didehydrogenation to form the corresponding benzobiphenylenes (S29 and S30) but the barriers for such processes are too high to be accessible $(\sim 100$ and $\sim$ $84 \mathrm{kcal} / \mathrm{mol}$, respectively, as presented in Figure 1, panel (c)).

To summarize the results presented in Figure 1, the reactions between o-benzyne and naphthalene proceed through several pathways among which the concerted channel is characterized by the lowest entrance barrier and leads to the formation of anthracene and acetylene. Based on the B3LYP/6-311G(d,p) calculations, addition to the $\alpha$ - and $\beta$-carbons also may lead to the formation of the same products through the bicyclo intermediate S1 (dibenzobicyclo[2.2.2]octatriene) or through a series of isomerization steps. The pathways to the other three-ring fused compound, phenanthrene, are possible but require higher energies, while the formation of the benzobiphenylenes is energetically unfavorable. It is also important to underline the fact that the entropies of the entrance transitions states with the lowest energies (TS1 for the concerted pathway, TS3 and TS27 for the stepwise pathways, Figure 1) are very similar. If we use the harmonic oscillator approximation, the corresponding entropies at $1000 \mathrm{~K}$ are $222.2 \mathrm{kcal} / \mathrm{mol}, 222.3$ $\mathrm{kcal} / \mathrm{mol}$, and $222.7 \mathrm{kcal} / \mathrm{mol}$, respectively. Thus, the entropic factor will not play a significant role in the determination of the branching ratios. 
Due to the importance of the o-benzyne + benzene CAF mechanism for the formation of naphthalene in shock tube experiments ${ }^{7,12}$, higher-level single-point energy calculations were performed with quantum chemistry composite methods (CBS-QB3, G3(MP2)B3, and G3B3) on both the $\left(\mathrm{o}_{-} \mathrm{C}_{6} \mathrm{H}_{4}+\mathrm{C}_{6} \mathrm{H}_{6}\right)$ and the (o- $\mathrm{C}_{6} \mathrm{H}_{4}+\mathrm{C}_{10} \mathrm{H}_{8}$ ) cycloaddition/fragmentation pathways. As mentioned above, these calculations are not affected by spin contamination, contrarily to the addition steps which should be analyzed using higher level methods. The relative energies calculated with the different methods are compared in Table 1 . The G3(MP2)B3 and the G3B3 methods provide very similar results, in particular concerning the energies of the transition states. The energies of the bicyclo intermediates (benzobicyclo[2.2.2]octatriene $\left(\mathrm{C}_{6} \mathrm{H}_{4} \mathrm{C}_{6} \mathrm{H}_{6}\right)$ and dibenzobicyclo[2.2.2]octatriene (S1)) formed by Diels-Alder reactions and the energies of the products differ between 1 and $2 \mathrm{kcal} / \mathrm{mol}$. The CBS-QB3 energies for the $\left(\mathrm{o}-\mathrm{C}_{6} \mathrm{H}_{4}+\mathrm{C}_{6} \mathrm{H}_{6}\right) \mathrm{CAF}$ are similar to the corresponding G3(MP2)B3 ones, with a maximum discrepancy of around $1 \mathrm{kcal} / \mathrm{mol}$ for the transition state of the fragmentation step to naphthalene and acetylene. Concerning the o-benzyne + naphthalene reactions, the CBS-QB3 energies are slightly lower compared to the G3 values, with maximum discrepancy of $\sim 2 \mathrm{kcal} / \mathrm{mol}$. For comparison, the B3LYP values are also reported in Table 1, which show large discrepancies with respect to the energies obtained with the composite methods. Such discrepancies suggest that the DFT method may not be able to correctly account for the intermolecular interactions, confirming the necessity of future investigations with higher-level theories. Nevertheless the uncertainties in the absolute values, the energies in Table 1 indicate clearly how the cycloaddition step is favored for the o-benzyne + naphthalene reaction compared to the case of benzene (based on the composite methods, the entrance barrier in the former case is only $1 \mathrm{kcal} / \mathrm{mol}$, thus almost $5 \mathrm{kcal} / \mathrm{mol}$ lower than the $\left(\mathrm{o}-\mathrm{C}_{6} \mathrm{H}_{4}+\mathrm{C}_{6} \mathrm{H}_{6}\right)$ case $)$. These results are somehow in agreement with the only experimental results available in the literature, the study by Miller and Stiles in the early sixties ${ }^{4}$. The authors produced o-benzyne from the low-temperature pyrolysis of benzenediazonium-2-carboxylate in both benzene and naphthalene. While in the first case various products were measured suggesting the availability of different reaction pathways (as also discussed in detail in other experimental ${ }^{5,6}$ and theoretical studies ${ }^{2,3}$ ), the presence of naphthalene led to dibenzobicyclo[2.2.2]octatriene as the only detectable product, even if 
analytical limitations could have masked the presence of other minor products. Finally, the results presented in Table 1 indicate that dibenzobicyclo[2.2.2]octatriene (S1) is much more stable compared to benzobicyclo[2.2.2] octatriene $\left(\mathrm{C}_{6} \mathrm{H}_{4} \mathrm{C}_{6} \mathrm{H}_{6}\right)$, thus the fragmentation barrier forming anthracene + acetylene is much higher compared to the step from benzobicyclo[2.2.2] octatriene to naphthalene and $\mathrm{C}_{2} \mathrm{H}_{2}(\sim 58$ $\mathrm{kcal} / \mathrm{mol}$ and $48 \mathrm{kcal} / \mathrm{mol}$, respectively, based on the G3B3 energies).

\subsection{CAF between o-benzyne and multi-ring PAHs}

The results presented in the previous sections clearly indicate the presence of a low-energy concerted pathway involving o-benzyne and naphthalene which is similar to the one proposed in previous publications for the o-benzyne + benzene system ${ }^{2,3}$. The following question which will be addressed in this section concerns the possibility to extend the CAF mechanism to other reaction systems involving even larger intermediates. Thus, additional calculations were implemented on the cycloaddition/fragmentation reactions of o-benzyne with three- and four-ring compounds. The results of the B3LYP optimizations are shown in Figure 3. The 1,4-cycloaddition of o-benzyne to anthracene and the subsequent fragmentation lead to the formation of the four-ring acene, naphthacene. In addition, the reactants may undergo a second cycloaddition step which involves the carbons in position 5 and 6 of the PAH structure. In this case, a very stable intermediate, S32, is formed. Such intermediate may only undergo fragmentation back to the reactants. The chemical structure of phenanthrene provides the possibility to explore a different cycloaddition, the one involving the two opposite ring-junction carbon atoms of the three-ring structure. In this case the CAF steps lead to the formation of triphenylene and acetylene. Such pathway is in competition with the 1,4-cycloaddition and fragmentation to benzo[a]anthracene $+\mathrm{C}_{2} \mathrm{H}_{2}$. In order to further improve our understanding on the cycloaddition to the ring-junction atoms, the concerted reaction of o-benzyne with pyrene to form benzo[e]pyrene was also investigated. Concerning the four-ring PAH compounds, the reactions of o-benzyne with naphthacene are similar to the ones described for anthracene, with a competition between the growth steps to pentacene and the 5,6-cycloaddition to the stable $\mathbf{S 3 7}$ intermediate. On the other hand, three possible entrance steps 
have been considered for the PES of benzo[a]anthracene + o-benzyne, which include the 1,4-CAF to benzo[a]naphthacene and acetylene, the 5,6-cycloaddition to $\mathbf{S 3 9}$, and the 9,12-CAF to pentaphene + $\mathrm{C}_{2} \mathrm{H}_{2}$. Finally the 1,4-cycloaddition of o-benzyne to chrysene, triphenylene, and benzo[c]phenanthrene were investigated, including the subsequent fragmentation to benzo[b]chrysene, dibenzo[a,c]anthracene, and naphtho[1,2-a]anthracene, respectively. For the cases of benzo[a]anthracene, chrysene, and triphenylene the reactions between the o-benzyne and the ring-junction atoms were not considered due to the corresponding high entrance barriers observed for the cases of phenanthrene and pyrene, as discussed in the following paragraphs.

In order to understand the influence of the PAH size on the energy barrier for the o-benzyne CAF steps, the B3LYP barriers for the cycloaddition and fragmentation processes have been compared in Figure 4. If the acenes are considered (circles), as the size increases from benzene (1 ring) to naphthacene (4 rings) the entrance barriers decrease monotonically (Figure 4a). The differences in the energy barriers diminish with the size, thus it is reasonable to think that above a certain dimension the barriers become nearly constant. When the compounds are not constituted by linearly fused benzene rings (crosses), such as for example the cases of phenanthrene, benzo[a]anthracene, chrysene, triphenylene, and benzo[c]phenanthrene, the cycloaddition barriers are slightly higher compared to the previous cases. It is interesting to notice how all the entrance barriers for the non-linear structures are similar $(\sim 9.5 \mathrm{kcal} / \mathrm{mol})$ with the one corresponding to the 1,4-cycloaddition to benzo[a]anthracene $(\sim 8 \mathrm{kcal} / \mathrm{mol})$ being the lowest (just above the value for naphthacene, $\sim 7 \mathrm{kcal} / \mathrm{mol}$ ). This is possibly due to the fact that the ring which undergoes the cycloaddition process is adjacent to two linearly fused rings (compared to only one for the other cases) thus the reaction is less affected by the "non-linearity" of the PAH structure. More accurate calculations with reduced uncertainties in the energy estimates for large, multi-ring intermediates and transition states will be necessary to confirm this observation. As shown in Figure 4a, the 5,6-cycloaddition reactions are the ones with the lower barriers. The figure does not contain the cycloadditions to the two opposite ringjunction carbon atoms for which the barriers are relatively high (see Figure 3). Figure $4 \mathrm{~b}$ contains the 
fragmentation barriers which exhibit opposite trends compared to the cycloaddition ones. Indeed, such barriers increase along with the size of the acenes towards a nearly asymptotic value, while the fragmentation for the non-linear structures is favored. Once again, the barrier in the case of the bicyclo intermediate formed by 1,4-cycloaddition of o-benzyne to benzo[a]anthracene is the closest to the corresponding value of the acene series.

To summarize the results on the reactions of o-benzyne with PAH intermediates, the calculations show that the 1,4-cycloaddition steps are favored when large acenes are involved compared to the single-ring case, although the corresponding fragmentation steps require more energy. For molecules characterized by non-linearly fused rings, the entrance barriers are slightly higher compared to the acene ones although lower fragmentation barriers are present, while the 5,6-cycloadditions are the most energetically-favored pathways. Thus, the CAF mechanism is influenced mainly by the size of the stable PAH molecule, its structure (linearly or non-linearly fused), and the position of the reacting carbon atoms.

Before moving to the next chapter, another alternative pathway involving the cycloaddition to the PAH bay regions will be considered. As an example, calculations have been performed on the simplest system, the reaction between o-benzyne and phenanthrene (Figure 5). The 4,5-cycloaddition leads to the formation of the intermediate $\mathbf{S 4 4}$ through a $12.0 \mathrm{kcal} / \mathrm{mol}$ energy barrier, comparable to but slightly higher than the entrance barrier for the 1,4-CAF process $(9.8 \mathrm{kcal} / \mathrm{mol})$. The subsequent didehydrogenization step to form benzo[e]pyrene $+\mathrm{H}_{2}$ involves a barrier of only $17.2 \mathrm{kcal} / \mathrm{mol}$. S44 may also undergo two subsequent hydrogen migrations to form the intermediate $\mathbf{S 4 6}$, but the corresponding energy barriers are too high compared to the didehydrogenization process and even to the reverse barrier to the reactants. If produced, S46 would undergo didehydrogenization to benzo[e]pyrene $+\mathrm{H}_{2}$, the favored step compared to the possible fragmentation to triphenylene $+\mathrm{C}_{2} \mathrm{H}_{2}$. The cycloaddition to the bay region followed by didehydrogenization may definitely be a competitive process to the cycloaddition to the rings followed by fragmentation (CAF).

\subsection{CAF involving other diradicals}


Several pathways for the formation of o-benzyne have been discussed in the introduction section in relation to the experimental results obtained in shock tube pyrolytic experiments, including self-reaction between phenyl radicals $^{8}$ and thermal decomposition of the benzyl radical ${ }^{13}$. On the other hand, o-benzyne is also formed from the dehydrogenization of the phenyl radical at relatively high temperatures. The process involves an energy barrier between $76 \mathrm{kcal} / \mathrm{mol}^{23,24}$ and $78 \mathrm{kcal} / \mathrm{mol}^{25,26}$, considerably lower than the overall energy necessary for the fragmentation of $\mathrm{C}_{6} \mathrm{H}_{5}$ into $n-\mathrm{C}_{4} \mathrm{H}_{3}$ and $\mathrm{C}_{2} \mathrm{H}_{2}{ }^{23,24,26}$. Although high concentrations of o-benzyne may be produced at the typical engine conditions due to the presence of large amounts of phenyl radicals from the dehydrogenization or the $\mathrm{H}$-abstraction from benzene, the availability of o-benzyne diradicals may be limited by the presence of competing consumption pathways, such as reactions with acetylene (HACA mechanism ${ }^{27,28}$ ), self-recombination to form biphenylene ${ }^{8}$, and, very important at high temperatures, dissociation into acetylene and diacetylene (as investigated both experimentally and theoretically ${ }^{24,29,30}$ ). Benzene is not the only aromatic compound which may undergo didehydrogenization to form a diradical intermediate. The thermal decomposition of multi-ring structures may proceed in a similar fashion, starting from the dehydrogenization or H-abstraction by another radical (mainly $\mathrm{H}, \mathrm{OH}, \mathrm{O}$ ) which lead to the formation of a radical intermediate. The corresponding kinetic steps are usually modeled using kinetic parameters from the reactions involving benzene, even if specific studies concerning PAHs have been performed in the past (such as the work by Violi et al. ${ }^{31}$ on the hydrogen abstraction reactions by $\mathrm{H}$ atoms). In general, these steps are very important for modeling PAH growth and soot formation since they constitute the base for the subsequent addition of acetylenes as for the HACA mechanism. The formation of diradical compounds at high temperatures may be an alternative consumption path for the radical intermediates. In order to test this hypothesis, calculations have been performed at the G3(MP2)B3 level of theory on the dehydrogenization of various multi-ring radical compounds (Figure 6). The energy obtained for the decomposition of the phenyl radical to benzyne $+\mathrm{H}$ is $77.6 \mathrm{kcal} / \mathrm{mol}$, in the range of the previous estimates, and it will be used as a reference for evaluating the dehydrogenization barriers for larger radicals. The first observation that can be done looking at the various energies is that the barriers vary between 77 and $83 \mathrm{kcal} / \mathrm{mol}$, thus they are not very different. More in 
detail, the decomposition of the intermediates with radical sites in position 1 or 2 favors the formation of 1,2-diradicals. Indeed, the barrier for formation of the 2,3-diradicals (Figure 7, crosses) is 2-4 kcal/mol higher compared to the corresponding 1,2-diradical case (Figure 7, circles). Another important result is that the energy required to form the energetically favored 1,2-diradical increases with the number of rings (from $77.6 \mathrm{kcal} / \mathrm{mol}$ to $80-81 \mathrm{kcal} / \mathrm{mol}$ from 1 to $4 \mathrm{rings}$ ). Although these results necessitate additional validations with more accurate theories, the trends should be accurate. Finally, a difference can be observed between the anthracenyl and the phenathrenyl radicals, the latter requiring higher energies in order to undergo dehydrogenization to the more-stable 1,2-diradicals. Concerning the 3- and 4phenathrenyl radicals, they both may lead to the formation of 3,4-phenanthryne, with barriers equal to around $78 \mathrm{kcal} / \mathrm{mol}$ and $80 \mathrm{kcal} / \mathrm{mol}$, respectively. Once again, the barrier to the 2,3-phenanthryne is higher by $\sim 4 \mathrm{kcal} / \mathrm{mol}$. The 9-phenathrenyl radical can also be formed from phenanthrene, and the decomposition of such radical may lead to the 9,10-phenanthryne with a barrier which is comparable to the one for the phenyl radical. Finally, the formation of the 4,5-pyrene from the 4-pyrenyl radical is the step characterized by the minimum energy barrier, around $77 \mathrm{kcal} / \mathrm{mol}$. From a practical modeling point of view, the results presented in Figure 6 may be used to adjust the activation energy of the dehydrogenization reactions to derive an expression for the formation of multi-ring diradicals starting from Arrhenius expression of the simpler (phenyl $\rightarrow$ o-benzyne $+\mathrm{H}$ ) reaction. Such reaction has been already studied in detail in the previous investigations and the corresponding kinetic parameters were validated against experimental results concerning the decomposition of the single-ring aromatic compounds.

The formation of multi-ring diradicals at the high-temperature conditions encountered in modern combustion engines opens the possibility for alternative CAF pathways for PAH growth. The simplest case involves reactions with benzene, which also represents the most abundant aromatic compound available in typical combustion environments. The corresponding CAF steps are reported in Figure 8 . The 1,2- and 2,3-naphthynes may lead to the formation of phenanthrene and anthracene, respectively. In a 
similar fashion, 1,2- and 2,3-anthracyne can react with benzene and, through cycloaddition and fragmentation, form benzo[a]anthracene and naphthacene, respectively. Benzo[a]anthracene can also be produced starting from 2,3-phenanthryne, while the 1,2-phenanthryne + benzene reactions lead to chrysene. Triphenylene may also be produced by cycloaddition of 9,10-phenanthryne with $\mathrm{C}_{6} \mathrm{H}_{6}$ and subsequent fragmentation, while the pyryne diradicals CAF reactions leads to five-ring fused structures, benzo[e]pyrene and benzo[a]pyrene. The PES presented in Figure 8 are of course limited only to the concerted steps, but, based on the previous results, the corresponding entrance channels should be energetically favored over the addition reactions. The results can be divided into groups which exhibit similar B3LYP reaction barriers. Such barriers are presented in Figure 9. The entrance barriers for the 1,2diradicals (represented by circles, Figure 9a) are similar to the one for o-benzyne $(\sim 13 \pm 1 \mathrm{kcal} / \mathrm{mol})$. The cycloaddition of the 2,3-diradicals with benzene is energetically slightly favored although the corresponding reaction rates should be limited by the concentrations of such diradicals. In fact, based on the calculations presented in Figure 6, the 1,2-diradicals are produced through lower energy pathways. The 9,10-phenanthryne and the 4,5-pyryne have similar symmetric structures, where the diradical site is connected to two ring-junction carbon atoms, and the corresponding barriers are essentially identical $(\sim 15$ $\mathrm{kcal} / \mathrm{mol}$ ). In particular, the entrance barrier is slightly higher than the case of o-benzyne + benzene cycloaddition. Once formed, the bicyclo intermediates may undergo fragmentation to the products (Figure 9b). The barriers for the fragmentation reactions on the (1,2-diradicals + benzene) PES are similar to the ones for o-benzyne + benzene, while the bicylo intermediates on the (2,3-diradical + benzene) PES are more stable compared to the reactants. This aspect of course influences the reaction barriers which are larger compared to the 1,2-diradical cases. The fragmentation steps for the bicyclo intermediates from the reactions between 9,10-phenanthryne and 4,5-pyryne with benzene to triphenylene and benzo[e]pyrene + acetylene proceed through energy barriers which are similar to the 1,2-diradical cases. From a practical point of view, the results presented in Figure 8 indicate that the energy barriers for the CAF steps are mainly influenced by the position of the diradical site. For the case of 1,2-diradicals, the most abundant diradicals produced from the didehydrogenization of multi-ring intermediate compounds (Figure 6), the 
kinetic parameters for the o-benzyne + benzene reactions may be used as a first approximation (after adjusting the pre-exponential based on the multiplicity of the reaction pathways). Similar considerations apply for all the cases where the diradical site is adjacent to two ring-junction carbon atoms, as in 9,10phenanthryne and 4,5-pyryne. This is a very interesting result since it suggests how the CAF mechanism may be further extended to PAHs of any size and structure, including ring clusters produced from other reaction mechanisms (as the HACA). On the other hand, the 2,3-diradicals are even more reactive towards cycloaddition although their formation through dehydrogenization of $\mathrm{PAH}$ radicals is energetically unfavored. It is important to underline the fact that more detailed studies especially focused on the numerous contributions to the vibrational partition functions of such large reaction systems will be required for more accurate evaluations regarding the kinetics of the different pathways. Before concluding the analyses on the CAF reactions involving the different diradical intermediates, additional calculations will be presented in order to confirm the analogy between the multi-ring diradical CAF and the o-benzyne case. These calculations involve the reactions between the naphthyne diradicals and naphthalene (Figure 10). The fragmentation steps of the bicyclo intermediates $\mathbf{S 3 3}$ and $\mathbf{S 3 1}$ has been already reported in Figure 3 thus they are not presented here. As for the results in Figure 8, the cycloaddition of the 1,2-naphthyne has an energy barrier which is comparable to the one for the cycloaddition between o-benzyne and naphthalene (Table 1). Moreover, the barrier for the 2,3-naphthyne case is lower by around $1.5 \mathrm{kcal} / \mathrm{mol}$ compared to the previous case, reproducing the same trend observed in Figure 8. These results support the idea that the CAF mechanism is not much influenced by the size of the diradical, but mainly by the position of the diradical in the PAH structure as well as the size of the intermediate stable reactant involved in the reaction.

\section{Conclusions}

A comprehensive investigation on the reactions involving diradical intermediates and aromatic compounds has been performed for the first time using computational chemistry techniques. In particular, 
the role of the concerted cycloaddition/fragmentation reactions has been explored in detail as relevant to the formation of the typical soot building blocks.

The ab-initio calculations of the reactions between o-benzyne and naphtahlene confirm from a theoretical point of view that the reaction proceeds mainly through the formation of dibenzobicyclo[2.2.2] octatriene as observed experimentally ${ }^{4}$. A novel pathway which involves the fragmentation of dibenzobicyclo[2.2.2] octatriene has been proposed for the first time as relevant to the formation of anthracene, in analogy with the reactions of o-benzyne + benzene ${ }^{2,3}$. The stepwise addition channels have also been studied and are found to lead to numerous multi-ring intermediates, including the very stable dibenzo-cyclooctatetraenes. Further isomerization and fragmentation steps finally may produce the three-ring compounds if sufficient energy is provided to the system.

The energetics of the CAF steps was also evaluated using different composite methods, and the results highlight how the 1,4-cycloaddition reaction of the o-benzyne with naphthalene is favored compared to the corresponding ones with benzene. The influence of the PAH size on the CAF energy barriers was further analyzed by studying the reactions between o-benzyne and the three- and four-ring structures. The results indicate how the entrance barriers for the 1,4-cycloaddition decrease with the size in the case of linearly fused structures, while the relative energies of the corresponding transition states in the case of non-linearly fused PAHs is higher. The 5,6-cycloaddition steps are found to be the energetically favored pathways, while cycloaddition to the ring-junction carbon atoms is the least accessible.

The second part of the paper concerns the CAF reactions between different multi-ring diradicals and benzene as well as between the naphthynes and naphthalene. First, the relative energies of various two-, three-, and four-ring diradicals compared to the corresponding radical intermediates have been evaluated for the first time using the G3(MP2)B3 method. The results show how the formation of the 1,2-diradicals is favored and that the dehydrogenization energy barriers increase with the number of rings. The subsequent investigation on the reactivity of such diradicals indicates that the size of the diradical is not as important as the position of the diradical site for the determination of the cycloaddition/fragmentation energies. 
The present work confirms that the CAF mechanism could possibly play a significant role in the mechanisms of growth of PAH species and soot, bringing light on the central role of the different diradical intermediates. The results can be used as the base for estimating the kinetic parameters of the different reactions by comparison with the o-benzyne + benzene case, which has been already studied in the past and successfully used to explain the formation of naphthalene in shock tube pyrolytic studies. Future higher-level investigations implementing multireference methods will be necessary to clarify unresolved questions raised in the manuscript, as well as to refine the kinetics of the proposed CAF mechanism by providing the base for fundamental master equation kinetic analyses.

Acknowledgements. The research was supported in part by the Centre Informatique National de l'Enseignement Supérieur (CINES) through Occigen resources under grant number AP010710182.

Supporting Information Available. Included for each optimized stationary structure are the Cartesian Coordinates (Ấngströms) in Gaussian format. The values of the spin contamination for the molecules in Figure 1 are also reported. This information is available free of charge via the Internet at http://pubs.acs.org.

\section{References}

(1) Wang, H. Formation of Nascent Soot and Other Condensed-Phase Materials in Flames. Proc. Combust. Inst. 2010, 33, 41-67.

(2) Comandini, A., Brezinsky, K. Theoretical Study of the Formation of Naphthalene from the Radical $/ \pi$ Bond Addition between Single-Ring Aromatic Hydrocarbons. J. Phys. Chem. A 2011, 115, 5547-5559.

(3) Shukla, B.; Tsuchiya, K.; Koshi, M. Novel Products from $\mathrm{C}_{6} \mathrm{H}_{5}+\mathrm{C}_{6} \mathrm{H}_{6} / \mathrm{C}_{6} \mathrm{H}_{5}$ Reactions. J. Phys. Chem. A 2011, 115, 5284-5293.

(4) Miller, R. G.; Stiles, M. Reaction of Benzyne with Benzene and Naphthalene. J. Am. Chem. Soc. 1963, 85, 1798-1800. 
(5) Fields, E. K.; Meyerson, S. Benzyne by Pyrolysis of Phthalic Anthydride. Chem. Commun. 1965, 20, 474-476.

(6) Friedman, L.; Lindow, D. F. Primary and Secondary Products from Reaction of Benzyne and Benzene at Elevated Temperatures. J. Am. Chem. Soc. 1968, 90, 2329-2333.

(7) Comandini, A.; Malewicki, T.; Brezinsky, K. Chemistry of Polycyclic Aromatic Hydrocarbons Formation from Phenyl Radical Pyrolysis and Reaction of Phenyl and Acetylene. J. Phys. Chem. A 2012, $116,2409-2434$.

(8) Tranter, R. S.; Klippenstein, S. J.; Harding, L. B.; Giri, B. R.; Yang, X.; Kiefer, J. H. Experimental and Theoretical Investigation of the Self-Reaction of Phenyl Radicals. J. Phys. Chem. A 2010, 114, 82408261.

(9) Moriarty, N. W.; Brown, N. J.; Frenklach, M. Hydrogen Migration in the Phenylethen-2-yl Radical. J. Phys. Chem. A 1999, 103, 7127-7135.

(10) Frenklach, M. Reaction Mechanism of Soot Formation in Flames. Phys. Chem. Chem. Phys. 2002, 4, 2028-2037.

(11) Colket, M. B.; Seery, D. J. Reaction Mechanisms for Toluene Pyrolysis. Proc. Combust. Inst. 1994, $25,883-891$.

(12) Yuan, W.; Li, Y.; Dagaut, P.; Yang, J.; Qi, F. Investigation on the Pyrolysis and Oxidation of Toluene over a Wide Range Conditions. II. A Comprehensive Kinetic Modeling Study. Combust. Flame 2015, 162, 22-40.

(13) Derudi, M.; Polino, D.; Cavallotti, C. Toluene and Benzyl Decomposition Mechanisms: Elementary Reactions and Kinetic Simulations. Phys. Chem. Chem. Phys. 2011, 13, 21308-21318.

(14) Comandini, A.; Brezinsky, K. Radical/ $\pi$-Bond Addition between o-Benzyne and Cyclic C5 Hydrocarbons. J. Phys. Chem. A 2012, 116, 1183-1190. 
(15) Becke, A. D. Density-Functional Thermochemistry. III. The Role of Exact Exchange. J. Chem. Phys. 1993, $98,5648-5652$.

(16) Lee, C.; Yang, W.; Parr, R. G. Development of the Colle-Salvetti Correlation-Energy Formula into a Functional of the Electron Density. Phys. Rev. B 1988, 37, 785-789.

(17) Krishnan, R.; Binkley, J. S.; Seeger, R.; Pople, J. A. Self-consistent Molecular Orbital Methods. XX. A Basis Set for Correlated Wave Functions. J. Chem. Phys. 1980, 72, 650-654.

(18), Frisch, M. J.; Trucks, G. W.; Schlegel, H. B.; Scuseria, G. E.; Robb, M. A.; Cheeseman, J. R.; Scalmani, G.; Barone, V.; Mennucci, B.; Petersson, G. A., et al. Gaussian 09, Revision A.1; Gaussian, Inc.: Wallingford CT, 2009.

(19) Gonzalez, C.; Schlegel, H. B. An Improved Algorithm for Reaction Path Following. J. Chem. Phys. 1989, 90, 2154-2161.

(20) Montgomery, J. A., Jr.; Frisch, M. J.; Ochterski, J. W.; Petersson, G. A. A Complete Basis Set Model Chemistry. VI. Use of Density Functional Geometries and Frequencies. J. Chem. Phys. 1999, 110, 28222827.

(21) Montgomery, J. A., Jr.; Frisch, M. J.; Ochterski, J. W.; Petersson, G. A. A Complete Basis Set Model Chemistry. VII. Use of the Minimum Population Localization Method. J. Chem. Phys. 2000, 112, 65326542.

(22) Baboul, A. G.; Curtiss, L. A.; Redfern, P. C.; Raghavachari, K. Gaussian-3 Theory Using Density Functional Geometries and Zero-Point Energies. J. Chem. Phys. 1999, 110, 7650-7657.

(23) Madden, L. K.; Moskaleva, L. V.; Kristyan, S.; Lin, M. C. Ab Initio MO Study of the Unimolecular Decomposition of the Phenyl Radical. J. Phys. Chem. A 1997, 101, 6790-6797.

(24) Wang, H.; Laskin, A.; Moriarty, N. W.; Frenklach, M. On Unimolecular Decomposition of Phenyl Radical. Proc. Combust. Inst. 2000, 28, 1545-1555. 
(25) Davico, G. E.; Bierbaum, V. M.; DePuy, C. H.; Ellison, G. B.; Squires, R. R. The C-H Bond Energy of Benzene. J. Am. Chem. Soc. 1995, 117, 2590-2599.

(26) Wang, H.; Frenklach, M. Calculations of Rate Coefficients for the Chemically Activated Reactions of Acetylene with Vinylic and Aromatic Radicals. J. Phys. Chem. 1994, 98, 11465-11489.

(27) Frenklach, M.; Clary, D. W.; Gardiner, W. C.; Stein, S. E. Detailed Kinetic Modeling of Soot Formation in Shock-Tube Pyrolysis of Acetylene. Proc. Combust. Inst. 1985, 20, 887-901.

(28) Bockhorn, H.; Fetting, F.; Wenz, H. W. Investigation of the Formation of High Molecular Hydrocarbons and Soot in Premixed Hydrocarbon-Oxygen Flames. Ber. Bunsen-Ges. Phys. Chem. 1983, $87,1067-1073$.

(29) Moskaleva, L. V.; Madden, L. K.; Lin, M. C. Unimolecular Isomerization/Decomposition of OrthoBenzyne: Ab Initio MO/Statistical Theory Study. Phys. Chem. Chem. Phys. 1999, 1, 3967-3972.

(30) Xu, C.; Braun-Unkhoff, M.; Naumann, C.; Frank, P. A Shock Tube Investigation of H Atom Production from the Thermal Dissociation of Ortho-Benzyne Radicals. Proc. Combust. Inst. 2007, 31, 231-239.

(31) Violi, A.; Truong, T. N.; Sarofim, A. F. Kinetics of Hydrogen Abstraction Reactions from Polycyclic Aromatic Hydrocarbons by H Atoms. J. Phys. Chem. A 2004, 108, 4846-4852. 
Figures and Tables

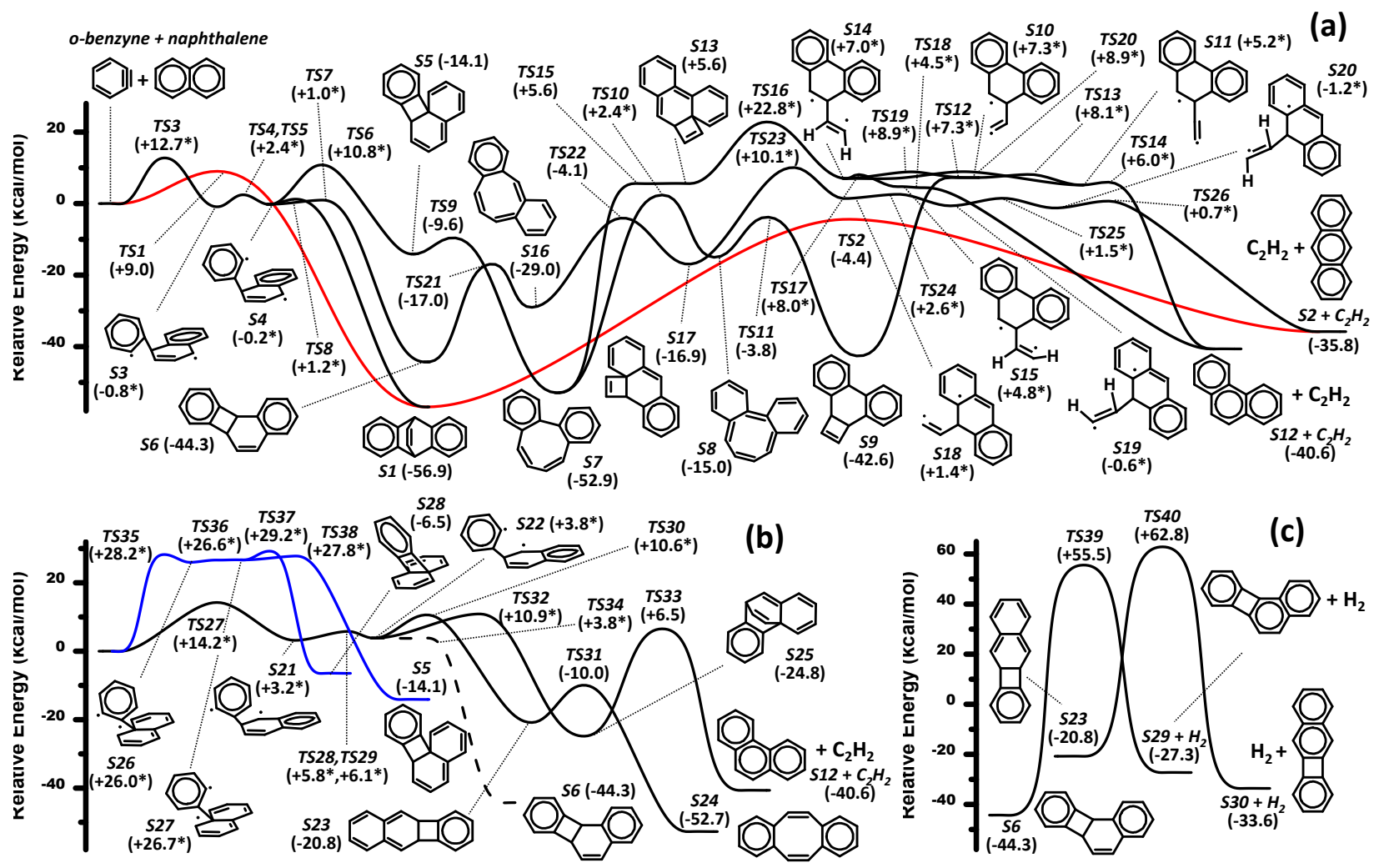

Figure 1. Potential energy surface for the reactions between o-benzyne and naphthalene. uB3LYP/6-311G(d,p) relative energies in kcal/mol, including ZPVE. Energies marked with an asterisk are affected by spin contamination (see Supporting Information for corresponding $<\mathbf{S}^{2}>$ values).

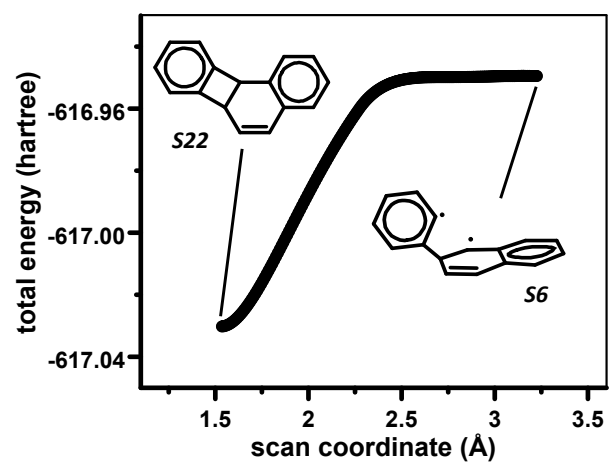

Figure 2. Potential energy surface scan varying the C-C distance between the two radical sites in S22 to the formation of S6. 
Table 1. Relative energies in kcal/mol for 1-4-CAF between o-benzyne and benzene/naphthalene.

\begin{tabular}{|c|c|c|c|c|}
\hline & $B 3 L Y P / 6-311 G(d, p)$ & $C B S-Q B 3$ & G3(MP2)B3 & G3B3 \\
\hline $0-\mathrm{C}_{6} \mathrm{H}_{4}+\mathrm{C}_{6} \mathrm{H}_{6}$ & 0.0 & 0.0 & 0.0 & 0.0 \\
\hline TS $\left(0-\mathrm{C}_{6} \mathrm{H}_{4}+\mathrm{C}_{6} \mathrm{H}_{6} \rightarrow \mathrm{C}_{6} \mathrm{H}_{4} \mathrm{C}_{6} \mathrm{H}_{6}\right)$ & 12.9 & 4.9 & 5.5 & 5.5 \\
\hline $\mathrm{C}_{6} \mathrm{H}_{4} \mathrm{C}_{6} \mathrm{H}_{6}$ & -43.3 & -56.8 & -56.4 & -58.1 \\
\hline $\mathrm{TS}\left(\mathrm{C}_{6} \mathrm{H}_{4} \mathrm{C}_{6} \mathrm{H}_{6} \rightarrow \mathrm{C}_{10} \mathrm{H}_{8}+\mathrm{C}_{2} \mathrm{H}_{2}\right)$ & -0.4 & -10.5 & -9.3 & -9.6 \\
\hline $\mathrm{C}_{10} \mathrm{H}_{8}+\mathrm{C}_{2} \mathrm{H}_{2}$ & -39.4 & -40.2 & -40.3 & -41.3 \\
\hline $\mathrm{o}-\mathrm{C}_{6} \mathrm{H}_{4}+\mathrm{C}_{10} \mathrm{H}_{8}$ & 0.0 & 0.0 & 0.0 & 0.0 \\
\hline TS1 $\left(0-\mathrm{C}_{6} \mathrm{H}_{4}+\mathrm{C}_{10} \mathrm{H}_{8} \rightarrow \mathrm{S} 1\right)$ & 9.0 & 0.2 & 1.1 & 1.0 \\
\hline S1 & -56.9 & -71.3 & -69.9 & -71.8 \\
\hline $\mathrm{TS2}\left(\mathrm{S} 1 \rightarrow \mathrm{a}-\mathrm{C}_{14} \mathrm{H}_{10}+\mathrm{C}_{2} \mathrm{H}_{2}\right)$ & -4.4 & -15.0 & -13.4 & -13.8 \\
\hline $\mathrm{a}-\mathrm{C}_{14} \mathrm{H}_{10}+\mathrm{C}_{2} \mathrm{H}_{2}$ & -35.8 & -37.2 & -36.7 & -37.6 \\
\hline
\end{tabular}



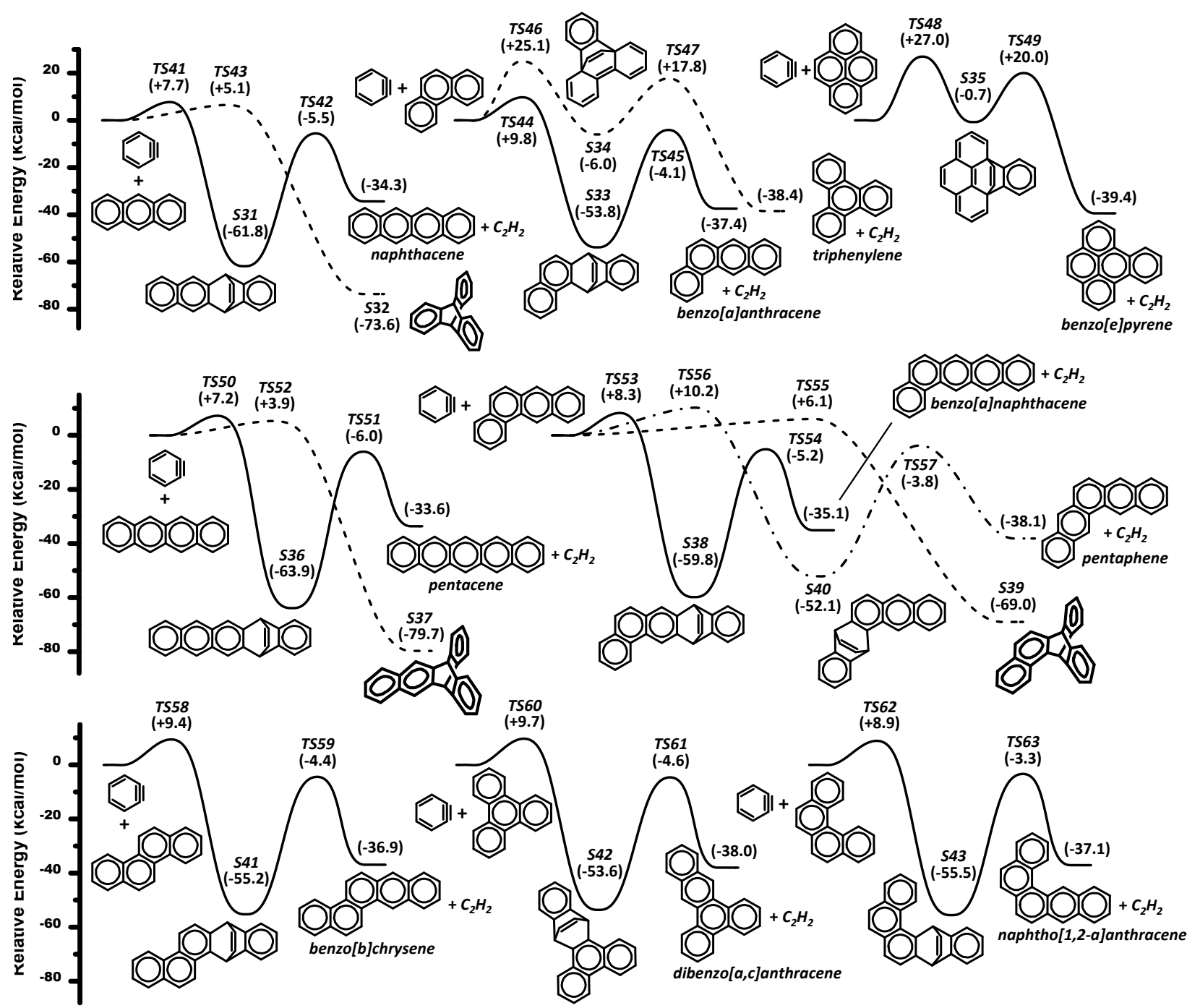

Figure 3. Potential energy surface for the CAF reactions between o-benzyne and three- and four-ring PAHs. uB3LYP/6-311G(d,p) relative energies in $\mathrm{kcal} / \mathrm{mol}$, including ZPVE. 

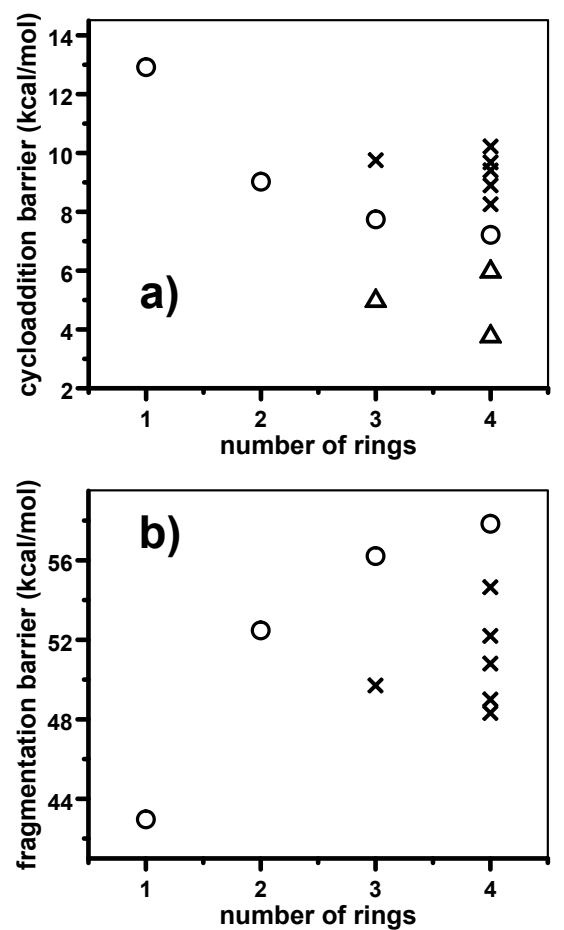

Figure 4. uB3LYP/6-311G(d,p) energy barriers in kcal/mol for the CAF reactions in Figure 3. Circles: 1,4CAF - linearly fused structures; crosses: 1,4-CAF - non-linearly fused structures; triangles: 5,6-CAF.

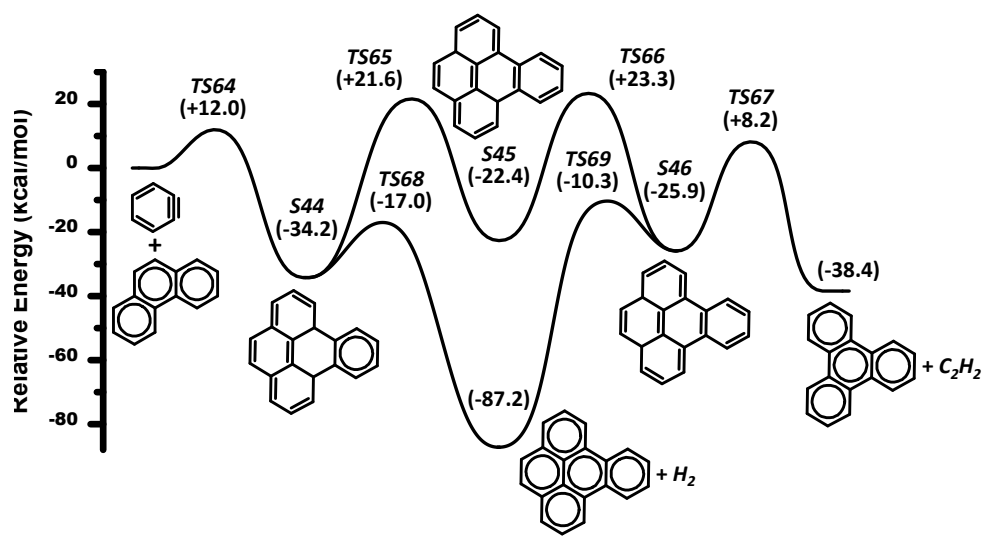

Figure 5. Cycloaddition of o-benzyne to the bay region of phenanthrene. uB3LYP/6-311G(d,p) relative energies in $\mathrm{kcal} / \mathrm{mol}$, including ZPVE. 


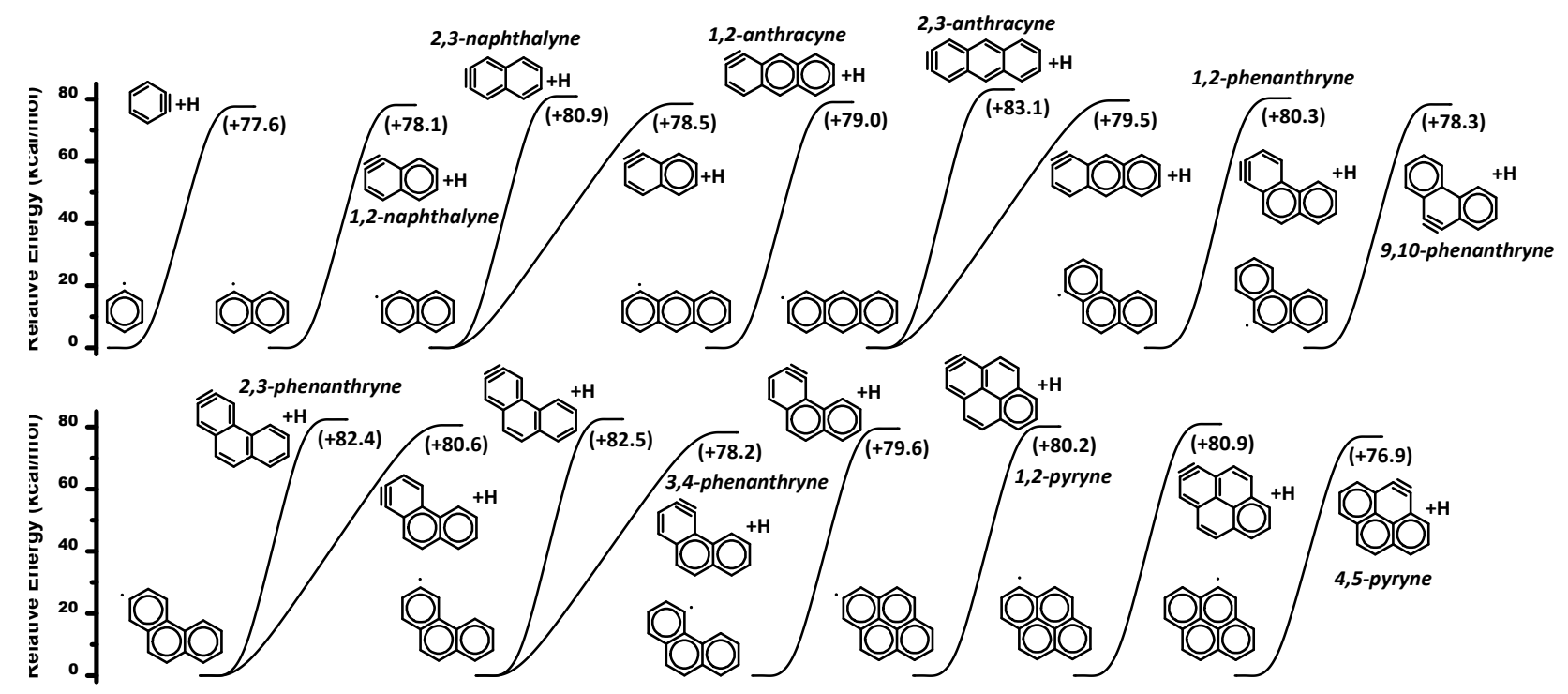

Figure 6. Potential energy surface for the the dehydrogenization of PAH radicals. G3(MP2)B3 relative energy in $\mathrm{kcal} / \mathrm{mol}$.

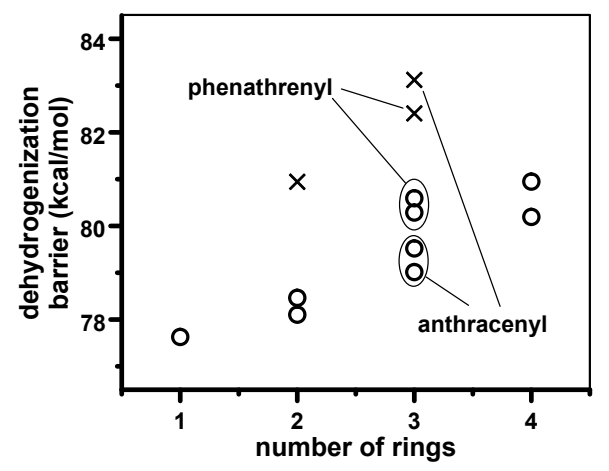

Figure 7. G3(MP2)B3 energy barriers in $\mathrm{kcal} / \mathrm{mol}$ for the dehydrogenization of 1- and 2- PAH radicals.

Formation of 1,2-diradicals (circles); 2,3-diradicals (crosses). 

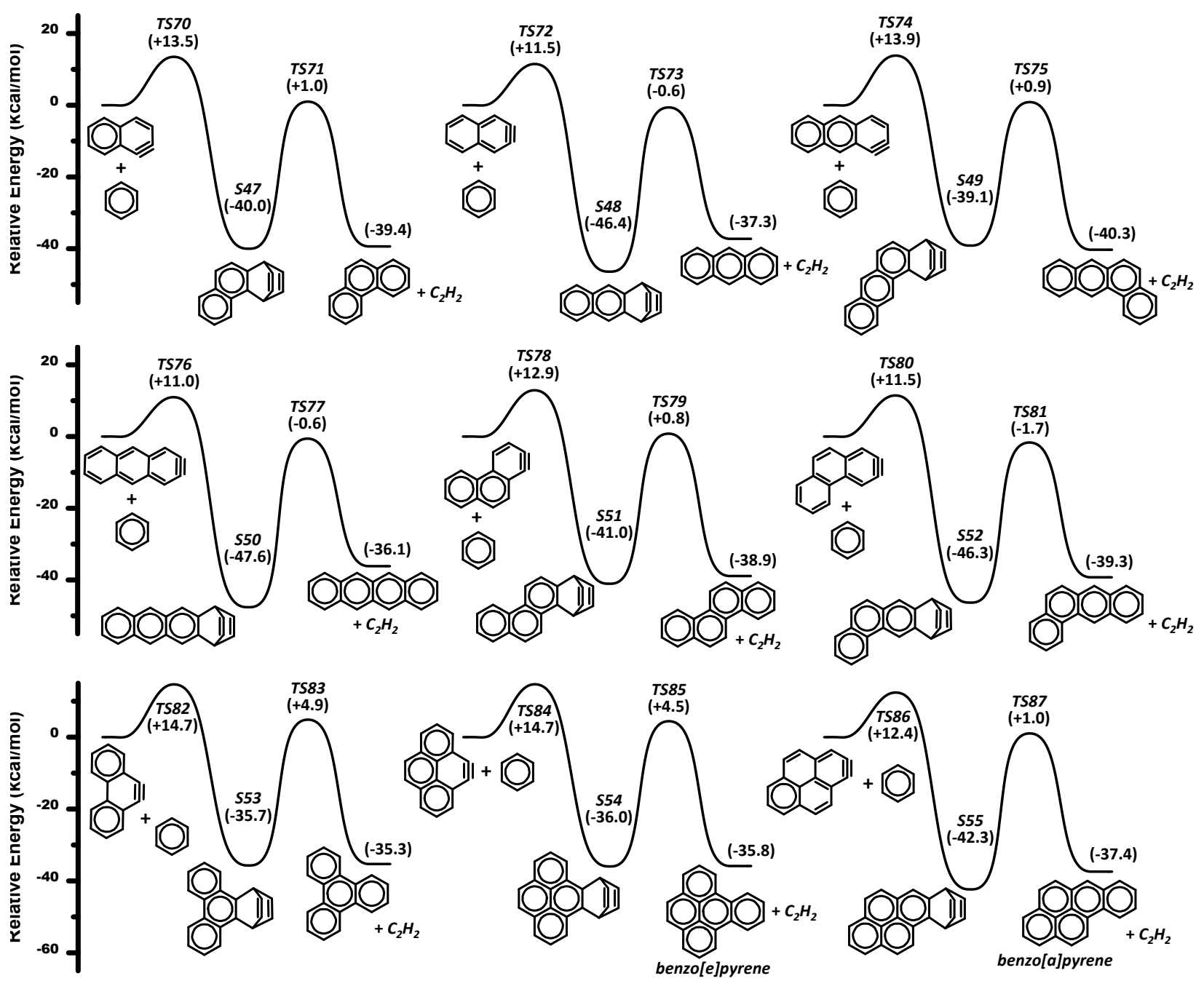

Figure 8. Potential energy surface for the CAF reactions between different diradicals and benzene.

uB3LYP/6-311G(d,p) relative energies in $\mathrm{kcal} / \mathrm{mol}$, including ZPVE. 

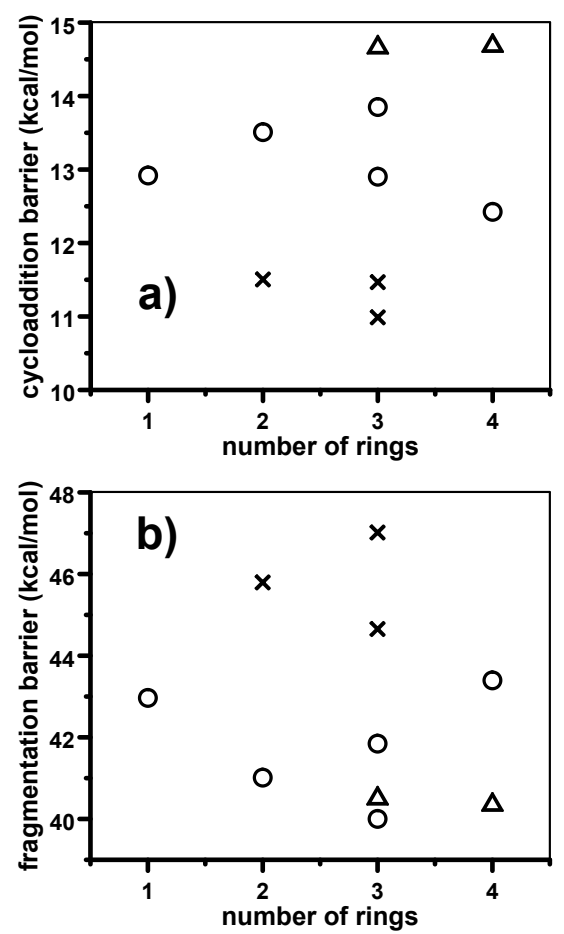

Figure 9. uB3LYP/6-311G(d,p) energy barriers in kcal/mol for the CAF reactions in Figure 8. Circles: 1,2diradicals + benzene; crosses: 2,3-diradicals + benzene; triangles: 9,10-phenanthryne/4,5-pyryne + benzene.
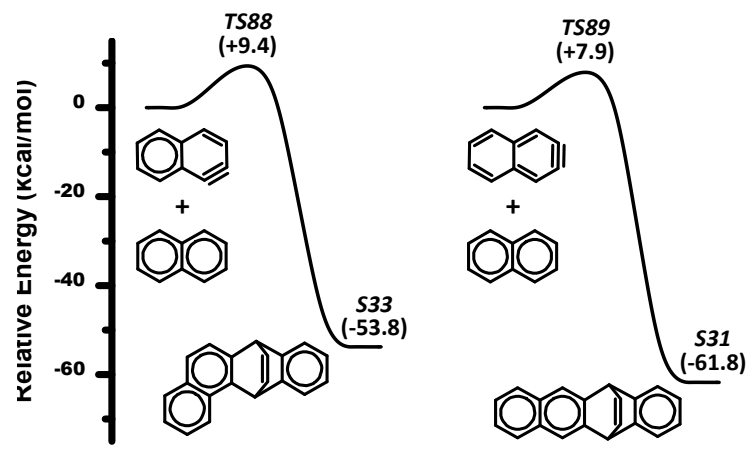

Figure 10. 1,4-cycloaddition between naphthyne diradicals and naphthalene. uB3LYP/6-311G(d,p) relative energies in $\mathrm{kcal} / \mathrm{mol}$, including ZPVE. 


\section{Table of Contents (TOC) Graphic}

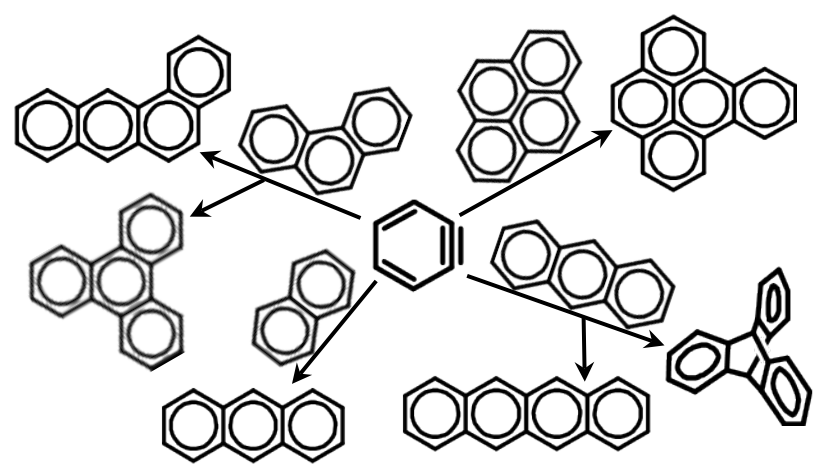

